\title{
Supporting the Growth of Global Citizenship Educators
}

\author{
Marianne Larsen and Lisa Faden \\ University of Western Ontario
}

\begin{abstract}
This paper presents the results of a study, which was a part of a broader project to develop and pilot test a global citizenship education (GCE) teaching kit. This study involved examining a group of typical teachers' perceptions, attitudes and beliefs about becoming global citizen educators. The study posed the question, "Can providing teachers with global citizenship education resources and supporting them in the implementation of these resources improve their capacity to be effective global educators?" We can infer from our study that there is mainstream appeal amongst social studies teachers for GCE. However, there are a number of limitations and barriers that prevent even those committed to global citizenship education from implementing GCE in their classrooms. Therefore, we argue that it is critically important to provide teachers with sustainable supports such as curriculum aligned teaching materials and professional development opportunities to become global citizenship educators.
\end{abstract}

The increased importance of globally-minded models of citizenship is reflected in recent research in citizenship education (Davies, 2006; Davies, Evans, \& Reid, 2005; Demaine, 2002; Gaudelli 2003). Bottery (2006) argues that education professionals "are at an important crossroads" at which they must choose to either embrace a global awareness in order to promote the public good or else retreat into insularity (pp. 111-112). To support those who decide to choose the path of global awareness, various curricular initiatives, such as the one described in this paper, have been recently developed.

This paper presents the results of a study that was a part of a broader project to develop and pilot test a global citizenship education teaching kit. The study involved examining a group of elementary school

The authors wish to acknowledge the support of the Canadians International Development Agency (CIDA) which funded the creation of the ACT! teaching kit through the Global Classroom Initiative (GCI). GCI financially supports projects that develop and deliver schoolbased, global education resources and activities. The teaching kit is available at www.tvdsb.on.ca/ act

Marianne Larsen is Assistant Professor of education at the University of Western Ontario and can be reached at mlarsen@uwo.ca. Lisa Faden is a doctoral candidate at the University of Western Ontario and can be reached at 1faden@gmail.com. 
teachers' perceptions, attitudes, and beliefs about becoming global citizen educators. We were particularly interested in the views of "typical" teachers, those who identified themselves as not exceptionally committed to global citizenship education (GCE) and as non-activists. The study posed the question, "Can providing teachers with global citizenship education resources and supporting them in the implementation of these resources improve their capacity to be effective global educators?" The answer, as demonstrated through our study, is clearly yes.

The paper is organized into three sections. In the first, we introduce the ACT! Active Citizens Today: Global Education for Local Schools project, describing the process behind the development of this curriculum resource and the methodology of this research study. We then turn our attention to analyzing the data from the study in order to understand the role of the teacher in GCE. We review the participants' attitudes towards GCE, the limitations and barriers they claim to face in implementing global education in their classrooms, and finally the degree of their growth as global educators over the course of the study. In the last part of the paper we locate our findings in the context of other literature on teachers' attitudes towards GCE and conclude with the implications of our study.

We can infer from our study that there is mainstream appeal for GCE amongst social studies teachers. However, there are a number of limitations and barriers that prevent even those committed to GCE from implementing it in their classrooms. Therefore, we argue that it is critically important, especially in an era of educational accountability and standards, to provide teachers with sustainable supports such as curriculum aligned teaching materials and professional development opportunities to become global citizenship educators.

\section{Defining and Implementing GCE: The Active Citizens Today (ACT!) Project}

Definitions of global education, global citizenship education, and citizenship education, have been hotly debated in the research literature for many decades. Gaudelli (2003) has noted the confusion about global education from within the field itself, pointing out that the vastness of the field makes an inclusive definition elusive. Indeed, as Popkewitz (1980) has noted, rather than being a tightly defined field, "global education" operates as a slogan, designed to create a mood with which people can affiliate particular pedagogical practices. Similar arguments have been made about the contested and complex nature of citizenship education and GCE (Tanner, 2007).

In their Critique of "Global Education" and "Citizenship

Education," Davies, Evans and Reid (2005) state, "The question for education is how to come to grips with the changing nature of citizenship in a 
globalising world" (p. 72). Davies et al. argue that current nation-centred models of citizenship education are outdated and that citizenship education curriculum needs to develop post-national conceptions of society. While national citizenship is a political reality formalized by laws and political institutions, global citizenship is a more abstract concept that indicates a recognition that individuals have ethical responsibilities to the global community. L. Davies (2006) argues that while global citizenship is an abstraction, it is one that captures a growing consensus on the importance of teaching students to understand their actions, as well as their rights and responsibilities, within a global network. L. Davies also concludes that GCE goes beyond global education's emphasis on global interconnectedness in order to promote an active model of citizenship. This active approach to citizenship is evident in GCE's emphasis on social justice, human rights, and peace activism:

These imply action in that if one perceives injustice and/or abuse of rights, one is more likely to seek ways at least to publicize these; similarly, if one learns about the links between conflict and interpretations of culture, one is less likely to accept passively the imperative of unquestioning adherence to cultural traditions (L. Davies, 2006, p. 6)

Within the framework of this active approach to citizenship within a Canadian context, the Active Citizens Today (ACT!) project was designed to meet the need for instructional materials for social studies teachers following the 2004 Ontario grade 6 curriculum change from the economics-focused "Canada and Its Trading Partners" to the more globally-minded "Canada's Links to the World." Together individuals from the school board, the faculty of education, and Free the Children, a non government organization, conceptualized, wrote, and edited the ACT! Active Citizens Today: Global Education for Local Schools teaching kit, which provides educators with over 35 ready-made lesson plans, black line masters, and assessment tasks.

The rationale behind the $A C T$ ! teaching kit recognizes that schools must teach students that they live in an interconnected and interdependent world and that education for global citizenship requires educators who can help students develop the knowledge, skills, and attitudes that they need to effect change both locally and globally. According to L. Davies's (2006) model, GCE fosters in students a sense of belonging to this global world and aims to build a global culture of peace and social justice through the promotion of values, attitudes, and behaviours which enable the realization of democratic ideals, sustainable development, and human rights for all.

The $A C T$ ! project is dedicated to promoting an active model of citizenship that helps students to be socially aware, to reflect critically about 
social, political and economic issues, and to enact positive social change (Crick, 2007; Davies \& Evans, 2002). Through the lessons and assessment tasks in the teaching kit, students come to understand how their actions affect the lives of people around the world and how they can change people's lives, for better or worse. Project writers worked from the premise that developing a global perspective would enrich students' understanding of human cultures so that they can respect people with diverse beliefs and experiences. In line with accepted understandings of the activist component of GCE (in relation to global education), the teaching kit aimed to support global citizenship educators in teaching students to take an active role in confronting injustice and inequality, both locally and globally. In this respect, the $A C T$ ! teaching kit project recognizes the potential and responsibility of both teachers and students as global citizens to be change agents in an interconnected and interdependent world (Bickmore, 1999; L. Davies, 2006; Oxfam, 2006).

\section{Research Methodology}

\section{Research Design: Data Sources and Timeline}

The ACT! Active Citizens Today teaching kit was written and edited in the summer of 2006. In the fall an information letter about the project and request for teachers to participate in a study to pilot the teaching kit was sent out to all junior division educators in the local public school board. The teachers who volunteered for the study attended a professional development workshop in November to provide them with an overview of GCE, the ACT! project and to review the expectations for being involved in the study.

Using a qualitative research approach, the broader project examined four data sets. Participants were asked to complete an online pre-survey before beginning to teach the $A C T$ ! lessons in order to measure their values, attitudes, and perceptions about GCE. A post-survey to measure teachers' values and perceptions about being involved in the study was administered at the end of the study. In total, thirteen teachers completed both the pre-survey and post-survey. From January to June 2007, the researchers visited classrooms and were able to observe twelve social studies educators teaching lessons from the resource kit. Each of these observations was followed by a semi-structured interview eliciting the teacher's feedback on their experience with the teaching kit and views about being a global educator. These interviews comprised the second data set for this study. At the end of the school year, the teachers completed a detailed questionnaire about each lesson, the assessment tasks, and overall objectives of the teaching kit. They also attended a debriefing session in June to share their feedback about being involved in the study, challenges and successes they encountered, and 
general impressions of the lessons and assessment tasks of the teaching kit. The final data source was the tape recording of this three-hour professional development and debriefing session.

Although the $A C T$ ! teaching kit project involved four data sources, the study which we are reporting on here draws its data only from the pre and post-surveys, semi-structured interviews, and debriefing session. Taped data from the interviews and debriefing session was transcribed, coded, and triangulated with the survey data to carry out the final analysis presented below.

\section{Research Participants}

Data for this paper is drawn from the 13 teachers ( 11 females and 2 males) who participated in piloting the teaching kit and completed the pre and post-surveys. Three-quarters (10) identified themselves as being from whiteEuropean ethnic background, two Native Canadian/First Nations and the remaining as "Other." There was a range in terms of teaching experience with $25 \%$ having taught fewer than 3 years; $25 \% 4-6$ years; $18 \% 7-15$ years and $30 \%$ more than sixteen years. All of the participants volunteered for this study, thus limiting the sample to those teachers who have already indicated their interest in GCE. The sample for this study is small for two reasons. First, one of the roles of the project facilitators was to support the teachers who have volunteered to pilot the teaching kit. To this end, it was deemed necessary to limit the number of participants so that the support offered would remain substantive and meaningful. In addition, the smaller sample size, a common feature of qualitative research methodology, provided a more in-depth understanding of teachers' values and attitudes towards global education, as well as the challenges they faced in implementing GCE in their schools. Finally, all teachers involved in the study were teaching in elementary schools in a public school board that serves the third largest student population in Ontario in an area spanning over 7,000 square kilometers. Approximately half of the participants worked in sub-urban (or semi-urban) schools and the other half in rural schools or schools in small towns.

In recognition of the previously discussed social justice component of GCE, we were interested in documenting the participants' levels of political awareness and their perceptions of themselves as social and/or political activists. The thirteen teachers taking part in the study did not describe themselves as unusually politically aware or politically active. When asked, "Do you consider yourself politically aware?" only three respondents (27\%) answered "yes"; six answered "somewhat"; two answered "no"; and two did not respond. More significantly, when asked, "Do you consider yourself a political or social activist?" none answered "yes"; five answered "somewhat"; 
six answered "no"; and two did not respond. These findings, along with the demographic makeup of these teachers (primarily female and white), and range of teaching experience led us to conclude that our sample was comprised of typical teachers, largely reflective of the general make-up of the Ontario teaching profession.

\section{Findings and Discussion}

\section{Teachers'Attitudes toward Global Citizenship Education}

Despite the contested nature of global education and GCE in the literature (discussed in previous sections), some common understandings amongst the participants of this study emerged when they were asked at the start of the study what they thought "global education" means. Two key themes emerged from their responses. The first was an awareness of the global issues and events and the diversity of the world's cultures. The second theme was interconnections between students and the world around them and how one's own actions can affect others.

When asked to define "global citizenship education," the majority of participants remarked upon the action aspect of GCE. Most noted that the citizenship element of GCE indicated an emphasis on a more activist-based pedagogy, moving from teaching students about the world, to acting "to promote change." One respondent eloquently explained,

We are each a citizen of the globe. As we become more educated on what events and issues are taking place worldwide, then we have a duty to respond to them. We have to become educated and then we have to respond as citizens who care and want to act responsibly with a global conscience.

Others noted the need to go beyond teaching students about global issues to focus on their responsibility as global citizens to consider not only their own interests, but those of others outside of their own communities. Almost 80 percent of respondents defined GCE as teaching students to take action or teaching students that they have responsibilities toward the global community. Further, in order to gauge their attitudes about GCE, respondents were also provided with a list of statements about GCE and asked to indicate whether or not they agreed with them. All of the respondents strongly agreed or agreed with the following statements, demonstrating their commitment to GCE:

- It is important for students to learn about people and issues in other parts of the world. 
- It is important to teach students about cultural diversity, both locally and globally.

- I often teach students to value and respect cultures that are different from their own.

- Middle school students should learn about the gaps in poverty that exist locally and globally.

We can see how the participants in our study were attentive to both the perceptual or attitudinal dimension of global education, which has been emphasized by many of the main proponents of the field (Case, 1999; Werner \& Case, 1997); and to the activist component of GCE. Overall, these teachers' responses aligned with the most commonly accepted understandings of global education and GCE in their emphasis on learning about the world, its conditions and concerns. These findings are not surprising and are supported by other studies; thus there is a strong attitudinal predisposition toward global education and GCE amongst social studies teachers (Schweisfurth, 2006; Tucker, 1983).

\section{Limitations and Challenges to Teaching Global Citizenship Education}

Participants were asked what they consider to be the limitations and challenges to teaching GCE. Our research data shows that there are a number of related barriers or limitations to teaching GCE. First, all of the participants indicated that they felt limited by their own lack of knowledge about global issues and how to teach about global issues in the social studies classroom. As Tucker (1983) and Robbins, Francis, and Elliot (2003) have demonstrated, while the majority of teachers considered it important, many feel unprepared or unqualified to teach global education and GCE. This is related to the second barrier, the absence of existing accessible global education curriculum materials and teaching resources. Not surprisingly, given the lack of materials, all of the participants concurred that lack of time to develop new curriculum materials with a GCE focus presented another limitation. Along these lines, respondents also noted the lack of related professional development workshops or activities.

The absence of references to GCE in the official curriculum, and pressures to cover too many other important topics in the curriculum were viewed as full or partial barriers. One teacher, in the comments section of the survey, claimed that the emphasis on language and math in grade 6 and on EQAO (Education Quality and Accountability Office) testing in these subject areas preclude teachers from focusing on social studies at this grade level. Also, the majority of respondents also noted their own discomfort or fear in teaching controversial issues. In the pre-survey, $71 \%$ of respondents indicated that "feeling that these topics are too political" was either a barrier 
or a partial barrier to teaching GCE; $59 \%$ indicated that "fear of teaching controversial issues" was a barrier or a partial barrier. Indeed, one teacher elaborated as follows:

I do feel some areas are a little "touchy" in that I don't want to convey my own bias to the children, because I know that they take what I say as the "truth." I also don't want to scare them or "disturb" them emotionally too much. I want them to be aware, but not scared.

Likewise, one other teacher noted that he did not like teaching about global issues because of their depressing and overwhelming nature.

Fewer teachers regarded lack of support from their administration or other teachers as barriers to teaching GCE. However, one respondent noted that parental perspectives might present a barrier. Further, three teachers thought that the inappropriateness of teaching global issues to middle school students presented an obstacle to work in this field. This is surprising given that research literature has unequivocally demonstrated that children should be introduced to global issues and perspectives as early as possible and that the elementary years are the most appropriate time for doing so (Diaz, Massialas, \& Xanthopoulus, 1999; Evans, 1987; Giese \& Downing, 1994).

\section{Teachers' Growth as Global Citizenship Educators}

One of the main goals of the $A C T$ ! project was to support participating teachers in their growth as global citizenship educators. The teaching kit itself was developed with the needs of local teachers in mind. In addition, we provided teachers with support through professional development workshops, visits to their schools, and phone call and email correspondence.

Teachers responded to questions about their growth as global educators in the post-survey and during the post-observation interviews. The survey posed the question, "To what degree do you attribute any changes in your perceptions, values, and attitudes about global education to your involvement in this study?" Almost $85 \%$ claimed that they had experienced changes that were partially or completely related to their involvement in the study. Survey responses indicated that teachers' involvement in the ACT pilot study provided them with opportunities to connect their students to GCE. Some teachers described the advantages of being involved in the pilot project, as in this response:

Having access to the resources, ideas, and activities would be the most significant advantages to this pilot project. The information and activities prompted many conversations and learning opportunities for my students. They began to 
develop an understanding of the world beyond their community and their role in the larger picture.

Access to resources and related professional development opportunities was a recurring theme amongst participants and illustrates the urgent need for further on-going support and GCE teaching materials that are relevant and user-friendly.

Teachers also described their experiences participating in the study as enjoyable, as affecting their teaching practice, and as fulfilling a need to bring an activist-oriented global perspective to their students. Many noted the teaching kit's strength in enabling students to make connections between the local and the global, and how much the students in sub-urban and rural areas enjoyed the lessons, as illustrated by these quotations:

Most of the students in my class quite enjoyed the unit and several listed learning about the UN as one of their favourite activities of the school year. I felt the unit was relevant and very informative ... Students were very keen to take on a Social Action project and it has me wondering if we will start a smallscale NGO as a school committee.

Fabulous activities that students enjoyed and opened their eyes because it sparked their interest [and] reminded me how important the big picture is even in a small town school.

Participants recognized that the teaching kit provided them with an organized framework of lessons through which they could structure their social studies program. For example, one experienced teacher noted in an interview that the teaching kit gave him a framework or structure to work with and build upon. He explained, "I have believed strongly in the importance of this type of teaching, but I've never really approached it in an organized, thematic way, so it's given me the resources and the ideas to do that." Moreover, participants noted the importance of having access to GCE teaching materials that link directly to the Ontario social studies curriculum objectives, as they increasingly feel the pressure to ensure that they "cover" the curriculum.

Finally, the teachers, both experienced and those new to the profession, indicated that they learned a lot about global issues through their involvement in the study. Even those who professed to have come to the study with significant background in global issues and activism claimed that the resource provided them with a completely new way of approaching these issues in the classroom. As one teacher explained:

As a student I used to be involved in Oxfam and other organizations. But as a teacher and as an educator, it's a totally 
new take for me. So this is really nice, like framing things in a way that first world or northern kids will understand and the way that they'll understand their privilege, these are all really interesting questions for me.

Teachers with less background in global issues described their involvement in the $A C T$ ! pilot study as eye-opening, as is evident in these two interview responses:

It's changed me a lot, and I have learned so much. I'm a geographer, but not this kind of geography, where you're looking at world issues and organizations .... It's got me being more aware of it and wanting to do something. It's really been educational for me. I've enjoyed the learning.

Anytime you have to teach something globally, you always are learning new things. As someone who's not, say, up on all the global issues or whatnot, you know, it's definitely an eye-opener to see how much things are connected and how much we are definitely dependent on other people.

Finally, feedback from the professional development workshops revealed the real need to provide educators with ongoing opportunities to learn about how to incorporate GCE into their teaching, and to develop sustainable professional networks with like-minded educators.

\section{Teachers'Attitudes Towards Global Citizenship Education}

Empirical research on the implementation of global education in the classroom is limited (Gaudelli, 2003). Much less focuses on the role of the teacher as global citizenship educator, mirroring the paucity of literature on GCE itself. For this reason, we discuss literature here on teachers as global educators and citizenship educators, and hope with our own study to contribute to the newly emerging field of literature on GCE.

Merryfield's (1998) study on teacher implementation of global education noted that

Although there has been considerable rhetoric about the need for global education, little attention has been paid to how teachers are actually teaching about the world, its peoples, and global issues... We know very little about what actually happens in globally-oriented classrooms. (p. 345)

Three recent studies examine the role of teachers' beliefs and knowledge in shaping citizenship education and GCE - Schweisfurth (2006), Myers (2007), 
and Davies (2004). Schweisfurth (2006) and Myers (2007) both examine the practices of teachers who are exceptionally committed to citizenship education. Schweisfurth's study involved 6 teachers in the Toronto, Ontario area, while Myers' study included politically active teachers in Toronto and in Porto Alegre, Brazil. Both of these studies found that teachers who are committed to teaching students to be active citizens can do so, even if these practices require that teachers depart from the state-mandated curriculum and locate teachers outside of the mainstream of their profession.

Myers (2007) studied politically active teachers to understand how their political experiences and their beliefs about the nature of democratic citizenship shaped their teaching practice. Myers argues,

Official curricula at best provide "openings" for the type of citizenship education that aims to deepen democracy rather than maintain its elitist practice. It seems that for teachers to make use of such openings they may need to be active in politics themselves. (p. 20)

He concludes that without actual experience in political or social activism, professional-development activities may be insufficient to prepare teachers to develop active citizenship in their students. Similarly, Schweisfurth (2006) found that the commitment to GCE motivated teachers to stretch the provincial curriculum so that they could teach the topics that were meaningful to them. Teachers in this study devoted considerable time and energy to gathering the resources necessary to teach global citizenship. They utilized a network of likeminded teachers, non-governmental organizations (NGOs) and other institutions in order to share resources, ideas, and encouragement. However, unlike the teachers in Schweisfurth's Toronto-based study, the teachers in our study were not a part of a network of GCE educators. Further, our participants did not claim to have similar high levels of political experience as demonstrated by Myers' sample. If Schweisfurth and Myers shine a light on the practice of exceptional citizenship educators, then our study is designed to reveal how more typical teachers outside of urban centres may approach the subject of GCE.

Davies's (2004) study of teachers' perceptions of citizenship and enterprise in England and Hungary found that in both countries, teachers located in a provincial town reported a greater reluctance to break rules or disobey authority than those who taught in the national capitals. Davies's observation that the provincial teachers were more reluctant to deviate from the prescribed norms concurs with our observation that teachers were uneasy about the prospect of teaching controversial issues. It also was reflected in the insistence of the curriculum writers, who were also teachers in the local 
board, that the $A C T$ ! teaching kit must "cover the curriculum" prescribed by the province.

Schweisfurth (2006) and Myers (2007) research describes education for active global citizenship that is practiced on the margins by exceptionally motivated and politically active teachers. However, the $A C T$ ! project revealed that teachers who were provided with GCE teaching resources that are engaging and that are aligned with the provincial curriculum guidelines, were able to implement an active GCE curriculum and find the experience to be professionally satisfying. Thus, this study casts doubt on Schweisfurth's and Myers' contention that GCE appeals only to a small group of radical teachers. Moreover, our findings are consistent with Robbins et al.'s (2003) conclusions that pre-service teachers overwhelmingly support the teaching of global issues though the majority feel that they are insufficiently prepared to do so.

\section{Conclusions and Implications}

We can draw a number of conclusions from this study. We can infer from the broader study (and subsequent promotion of the teaching kit) that there is a desire amongst social studies school teachers for GCE teaching resources. The study demonstrates that teachers are likely only to embrace GCE with appropriate supports such as resources that are user-friendly, explicitly aligned with official curriculum expectations, and related professional development opportunities.

The reported success of the $A C T$ ! teaching kit suggests that GCE has a broad appeal among teachers, students, and school boards. Students as young as grade 6 , and presumably younger, can understand sophisticated concepts such as international development, nongovernmental organizations, social justice, and human rights, when these concepts are linked to their own experiences. All of the teachers who provided feedback for the study found the GCE content to be engaging for students, and were surprised and gratified by the degree to which their students became personally invested in their global studies. In fact, the $A C T$ ! pilot project was so successful that the Toronto District School Board has ordered 1000 hard copies of the ACT! teaching kit, despite the fact that the resource will be available for free in PDF form. Four other Ontario school boards also have ordered hard copies of the kit, in addition to the school board that sponsored the original project.

The need for teacher-friendly GCE materials is related to the limitations and barriers that participants noted. While a few noted their own lack of knowledge about and discomfort with teaching about global issues, the majority indicated that there were other "external" factors that prevented or limited them from engaging in GCE with their students. The most significant external factors included the pressures they are facing from accountability- 
based demands on their time. Participants noted that with the emphasis on time-consuming accountability practices such as performance appraisals and standardized testing in Language Arts and Mathematics, there is less time for curricular development in subjects such as social studies. This echoes other research that demonstrates the effects on teachers' work of managerial type reforms that privilege system efficiency, individual and organizational performance, and accountability (Larsen, 2005; Travers \& Cooper, 1996).

Survey and interview data also supports the conclusion that the study succeeded in addressing the question, "Can providing teachers with global citizenship education resources and supporting them in the implementation of these resources improve their capacity to be effective global educators?" Teachers indicated that their participation in the ACT! pilot study allowed them to incorporate desirable content, skills, and values related to GCE. Eleven of thirteen participants responded in the survey that positive changes in their "perceptions, values, and attitudes about global education" were either partially or completely related to their participation in the study. The evidence suggests that the study achieved the goals of promoting in teachers increased understanding of their roles as global citizens and global educators, as well as an increased efficacy in promoting GCE in their own classrooms.

The $A C T$ ! teaching kit and related professional development workshops were successful with teachers because they supported engaging and interactive learning and because the kit was compatible with (i.e. "covered") the official Ontario curriculum guidelines. To support the implementation of GCE, teachers should be provided with materials that are engaging, interactive, and compatible with curriculum expectations. The "Enabling Effective Support" strategy of the Department for International Development (U.K) concluded that there is a real and pressing need for the provision of supports for teachers involved in integrating the global dimension into their teaching (Department for International Development, 2003; see also Davies, Gregory \& Riley, 1999; Robbins, et al., 2003).

Furthermore, curriculum initiatives such as GCE, according to Evans (2003)

face unavoidable setbacks when they are disconnected or incompatible with broader school directions and/or contextual factors. Schools, organizationally, have tended to reinforce the norms of hierarchical control, and in so doing, have undermined the impact of certain types of curricular reform. ( $p$. 37)

Therefore, in order to mobilize the potential teacher support for GCE, it is essential to provide teachers with engaging curriculum materials and related professional development opportunities that respond to their practical needs and constraints they face in their work as elementary school teachers. 
There is some debate within the citizenship education and global education literature as to how politically informed and politically active teachers need to be in order to teach students to be active citizens. As noted earlier, the teachers in this study do not represent an unusually politically active sample, in contrast to the participants in studies of global citizenship educators by Schweisfurth (2006) and Myers (2007). These were a group of typical teachers in terms of their background knowledge, activist and teaching experience, gender, and race. While our pre-survey results indicated that the majority of teacher participants were concerned that the controversial or "too political" nature of global issues represented a partial barrier to teaching about them, teachers did not find this to be a problem with the GCE approach presented in the $A C T$ ! teaching kit.

The question that hangs over the enterprise of implementing GCE curriculum is whether a critical pedagogy like GCE can become part of the mainstream curriculum. In the mid-late 1980s, the political right attacked global education and world studies, predecessors to GCE, for being forms of indoctrination and politicization, contributing to the marginalization of those fields of study (Hicks, 2007). However, what this study shows is that GCE is not viewed by teachers as a radical concept. Both students and teachers in Ontario are interested in learning about social justice on a global scale, and there is widespread support for institutions, such as the United Nations and various international NGOs, that build international cooperation and peaceful conflict resolution. However, the constraints imposed by limitations on teachers' planning time and knowledge of global issues, as well as current pressures on teachers to cover the official curriculum, mean that GCE, which represents a new paradigm for citizenship education, can only be widely implemented with the development of curriculum aligned instructional materials that meet teachers' needs.

\section{References}

Bickmore, K. (1999). Elementary curriculum about conflict resolution: Can children handle global politics? Theory and Research in Social Education, 27(1), 45-69.

Bottery, M. (2006). Education and globalization: Redefining the role of the educational professional. Educational Review, 58(1), 95-113.

Case, R. (1999). Global education: It's largely a matter of perspective. In R. Case \& P. Clark. (Eds.). The Canadian Anthology of Social Studies. (pp. 75-82). Vancouver, British Columbia, Canada: Pacific Educational Press.

Crick, B. (2007). Citizenship: The political and the democratic. British Journal of Educational Studies, 55(3), 235-248. 
Davies, I. (2004). Citizenship and enterprise: Issues from an investigation of teachers' perceptions in England and Hungary. Comparative Education, 40(3), 363-384.

Davies, I., \& Evans, M. (2002). Encouraging active citizenship. Educational Review, 54(1), 69-78.

Davies, I., Evans, M., \& Reid, A. (2005). Globalizing Citizenship education? A critique of "global education" and "citizenship education". British Journal of Educational Studies, 53(1), 66-89.

Davies, I., Gregory, I., \& Riley, S. C. (1999). Good citizenship and educational provision. London: Falmer Press.

Davies, L. (2006). Global citizenship: abstraction or framework for action? Educational Review, 58(1), 5-25.

Demaine, J. (2002). Globalisation and citizenship education. International Studies of Education, 12(2), 117-128.

Department for International Development. (2003). Enabling effective support: Responding to the challenges of the global society: A strategy of support for the global dimension in education. London, UK: DFID.

Diaz, C. F., Massialas, B. G., \& Xanthopoulus, J. A. (1999). Global perspectives for educators. Boston: Allyn and Bacon.

Evans, C. (1987) Teaching a global perspective in elementary classrooms. The Elementary School Journal 87(5), 545-555.

Evans, M. (2003). Educating for citizenship in schools in Canada. Orbit, 33(2), 33-37.

Gaudelli, W. (2003). World class: Teaching and learning in global times. Mahwah, N.J.: Lawrence Erlbaum.

Giese, J., \& Downing, P. (1994). Forward. In J. Benegar, J. Johnston, \& L. Singleton (Eds.), Global issues in the middle school: Grades 5-8 (3rd ed.), iv. Denver, CO: Social Science Education Consortium and Center for Teaching International Relations.

Hicks, D. (2007). Principles and precedents. In D., Hicks \& C. Holden (Eds.), Teaching the global dimension: Key principles and effective practice (pp. 1-30). London: Routledge.

Larsen, M. (2005). A critical analysis of teacher evaluation policy trends. Australian Journal of Education, 49(3), 292-305.

Merryfield, M. (1998). Pedagogy for global perspectives in education: Studies of teachers' thinking and practice. Theory and Research in Social Education, 26(3), 342379.

Myers, J. P. (2007). Citizenship education practices of politically active teachers in Porto Alegre, Brazil and Toronto, Canada. Comparative Education Review, 51(1), 1-24.

OXFAM. (2006). Education for global citizenship: A guide for schools. Retrieved July 10, 2006 from, http://www.globaldimension.org.uk/docs/gcguide06.pdf

Popkewitz, T. P. (1980). Global education as a slogan system. Curriculum Inquiry, 10, 303-316.

Robbins, M., Francis, L. J., \& Elliot, E. (2003). Attitudes toward education for global citizenship among trainee teachers. Research in Education, 69, 93-98.

Schweisfurth, M. (2006). Education for global citizenship: teacher agency and curricular structure in Ontario schools. Educational Review, 58(1), 41-50.

Tanner, J. (2007). Global citizenship. In D. Hicks \& C. Holden (Eds.), Teaching the global dimension: Key principles and effective practice (pp. 150-160). London: Routledge. pp. 150-160. 


\section{Larsen \& L. Faden}

Travers, C. L., \& Cooper, C. L. (1996). Teachers under pressure: Stress in the teaching profession. London: Routledge.

Tucker, J. (1983). Teacher attitudes toward global education: A partial agenda for the future. Educational Research Quarterly, 8(1), 48-54.

Werner, W., \& Case, R. (1997). Themes in global education. In I. Wright \& A. Sears (Eds.), Trends and issues in Canadian social studies education (pp. 176-194). Vancouver, British Columbia, Canada: Pacific Education Press. 